\title{
A RESOLUÇÃO DE CONFLITOS POR MEIO DA MEDIAÇÃO NO ÂMBITO DA DEFENSORIA PÚBLICA
}

Guilherme Gomes Vieira

THE RESOLUTION OF CONFLICTS THROUGH THE MEDIATION LINKED TO THE PUBLIC DEFENDER 


\title{
A RESOLUÇÃO DE CONFLITOS POR MEIO DA MEDIAÇÃO NO ÂMBITO DA DEFENSORIA PÚBLICA
}

\author{
THE RESOLUTION OF CONFLICTS THROUGH THE MEDIATION LINKED TO THE PUBLIC
}

DEFENDER

\author{
Guilherme Gomes Vieira \\ Advogado \\ Pós-graduando em direito processual civil pelo Instituto Brasiliense de Direito Público. \\ Brasilia, Brasil \\ vieiraguilherme.g@gmail.com
}

\section{RESUMO}

Uma das finalidades da mediação é a de contribuir para o reestabelecimento das relações pessoais por intermédio de diálogos que promovam o respeito e a cooperação, considerando-se, para tanto, a situação de vulnerabilidade dos participantes. No Brasil, a mediação recebeu notável estímulo, inclusive na seara legislativa - com a promulgação da Lei no. 13.140, de 26 de junho de 2015, e do Código de Processo Civil de 2015, o que evidencia a importância atribuída ao referido instituto. Este estudo aborda a mediação como instrumento para a resolução de conflitos e visa à verificação da compatibilidade entre o aludido método de resolução de conflitos e os serviços prestados pela Defensoria Pública, verificando projetos instituídos por diferentes Defensorias Públicas. Posteriormente, analisa-se, de modo detalhado, o Projeto de Mediação e Conciliação para Resolução de Conflitos Extrajudiciais, promovido pela Defensoria Pública do Distrito Federal, o qual evidencia o sucesso do uso de mediaçáo como instrumento de resoluçáo de conflitos no âmbito da Defensoria Pública. Conclui-se que é interessante haver estímulos ao implemento de projetos vinculados à mediação no âmbito da Defensoria Pública, sobretudo em razão do fomento à resolução extrajudicial de litígios e dos benefícios obtidos pela sociedade.

Palavras-chave: Mediação. Defensoria Pública. Vulnerabilidade. Resolução de conflitos. Solução extrajudicial. 


\begin{abstract}
One of the purposes of mediation is to contribute to the reestablishment of personal relationships through dialogue that promotes respect and cooperation, considering, therefore, the situation of vulnerability of the participants. In Brazil, mediation received a remarkable stimulus, even in the legislative sphere - with the enactment of Law no. 13,140, of June 26 $6^{\text {th }}, 2015$ and the Code of Civil Procedure of 2015, which shows the importance given to this institute. This study deals with mediation as an instrument for the resolution of conflicts and aims at verifying the compatibility between the aforementioned method of conflict resolution and the services provided by the Public Defender, verifying projects instituted by different Public Defenders. Subsequently, a detailed analysis of the Project for Mediation and Conciliation for Resolution of Extrajudicial Conflicts, promoted by the Public Defender of the Brazilian Federal District, which evidences the success of the use of mediation as a conflict resolution instrument within the scope of the Public Defender's Office. It is concluded that it is interesting to have incentives to implement projects related to mediation in the scope of the Public Defender's Office, mainly because of the promotion of out-of-court settlement of litigation and benefits obtained by society.
\end{abstract}

Keywords: Mediation. Public Defender's Office. Vulnerability. Conflict resolution. Out-of-court settlement.

Data de submissão: 20/03/2017

Data de aceitaçáo: 13/06/2017

\title{
SUMÁRIO
}

INTRODUÇÃO 1. A MEDIAÇÃO COMO INSTRUMENTO DE RESOLUÇÃO DE CONFLITOS 2. A MEDIAÇÃO NA DEFENSORIA PÚBLICA 3. O PROJETO DE MEDIAÇÃO E CONCILIAÇÃO PARA RESOLUÇÃO DE CONFLITOS EXTRAJUDICIAIS. CONSIDERAÇÕES FINAIS. 


\section{INTRODUÇÁO}

A Defensoria Pública é a "instituiçáo de Estado destinada a prestar atendimento jurídico integral às pessoas em situaçáo de vulnerabilidade econômica ou social”" ${ }^{\prime}$. Desse modo, vê-se que aludida instituiçáo está fortemente vinculada ao conceito de acesso à justiça.

Noutra esteira, a Defensoria Pública auxilia na concretização do Estado Democrático de Direito, o qual, incorporado ao ordenamento jurídico brasileiro mediante previsão expressa da Constituição Federal, reflete a importância vinculada à cidadania e à presença no âmbito das discussóes públicas. ${ }^{2}$

Nesse contexto, nota-se um fenômeno intensificado diariamente, denominado crise da jurisdição. Em decorrência da globalização - e de seus inúmeros reflexos em diversas searas -, houve um estímulo no que concerne à confecção de demandas sociais traduzidas em ações judiciais. Desse modo, em face desse panorama, "o Poder Judiciário mostrou-se despreparado para responder a novas demandas sociais de forma eficiente e satisfatória" ${ }^{3}$

Considerando a necessidade de efetivação do direito de acesso à justiça e a enorme quantidade de processos judiciais em trâmite (99,7 milhôes de processos em 2014, de acordo com relatório do Conselho Nacional de Justiçấ), métodos alternativos de resolução de conflitos são estimulados, visando à melhor resposta para a lide e à menor duração do processo.

\section{A MEDIAÇÃO COMO INSTRUMENTO DE RESOLUÇÃO DE CONFLITOS}

Conforme mencionado, o Poder Judiciário enfrenta a crise da jurisdição, a qual o impede de "exercer a função jurisdicional de forma célere, eficaz e desburocratizada". Impede, portanto, a

$\overline{1}$ GODOY, A. E. de. Conflitos habitacionais urbanos: atuação e mediação jurídico-política da defensoria pública, 2015, p. 121.

2 CARVAlHO NETTO, M. de. A Hermenêutica Constitucional sob o Paradigma do Estado Democrático de Direito. In: OLIVEIRA, M. A. C. de (coord.). Jurisdição e Hermenêutica Constitucional, 2004, p. 34-37.

3 VASCONCELOS, F. H. de. Advocacia negocial: promoção do acesso à justiça pela desjudicialização dos conflitos, 2014, p. 75.

4 BRASIL. Dados estatísticos. Disponível em: http://www.cnj.jus.br/programas-e-acoes/politicanacional-de-priorizacao-do-1-grau-de-jurisdicao/dados-estatisticos-priorizacao. Acesso em: 17 mar. 2017.

5 VASCONCELOS, F. H. de. Advocacia negocial: promoção do acesso à justiça pela desjudicialização dos conflitos, 2014, p. 39-40. 
concretização de princípios constitucionais, notadamente no que concerne à razoável duração do processo e à efetiva apreciação de lesão ou ameaça a direito.

Importante destacar que não apenas deve ser assegurado aos jurisdicionados a celeridade na tramitação do processo judicial. É preciso, de forma concomitante e complementar, garantir a qualidade das decisóes proferidas pelo Poder Judiciário, consoante o que estabelece o art. 93, inciso IX, da Constituição Federal, a qual é refletida na substancial fundamentação utilizada pelos magistrados.

É incabível, desse modo, cogitar que a solução para a morosidade do judiciário equivalha à padronização e à massificação de decisóes judiciais sem que haja a necessária análise das peculiaridades do caso concreto. Ressalta-se que existem técnicas válidas previstas no ordenamento jurídico brasileiro que auxiliam na efetivação da razoável duração do processo ${ }^{6}$. Entretanto, é preciso haver cautela para não transformar a atividade jurisdicional em mero cálculo aritmético reproduzido em demandas, sob pena de se transpor o problema da quantidade para a seara da qualidade.

Diante do cenário da crise da jurisdição e, consequentemente, da obstruçấo do Poder Judiciário, surgiram métodos alternativos de resolução de conflitos, a exemplo da mediação, sem prejuízo do reconhecimento da indispensabilidade do exercício jurisdicional.

Mediação é o procedimento voluntário em que um terceiro intermedeia o conflito entre indivíduos, de forma a permitir a identificação dos aspectos favoráveis e desfavoráveis para a efetiva construçâo de soluçóes adequadas. Permite-se, portanto, a concretizaçáo da comunicaçáo mediante a autonomia da vontade das partes. Sobre o tema, esclarece Muñoz:

La mediación es un procedimiento a través del cual un tercero imparcial ayuda a las partes en conflicto a llegar a un acuerdo. La esencia de la mediación que refleja esta definición es la autonomía de la voluntad de las partes: son las partes las que llegan a un acuerdo, libremente, y auxiliadas por un tercero, que, consecuentemente, ha de ser imparcial. ${ }^{7}$

De acordo com Lília Sales, "a mediação tem por finalidade aproximar as partes e estimular, através do diálogo, o resgate dos objetivos comuns que possam existir entre os indivíduos

\footnotetext{
6 Súmula vinculante, recursos repetitivos, incidente de resolução de demandas repetitivas, entre outros.

7 MUÑOZ, H. S. La mediación: método de resolución alternativa de conflictos en el Proceso Civil Español. Revista Eletrônica de Direito Processual, ano 3, v. 3, jan-jun. 2009. "A mediação é um procedimento pelo qual um terceiro imparcial ajuda as partes em conflito a chegar a um acordo. A essência da mediação que reflete essa definição é a autonomia da vontade das partes: são as partes que chegam a um acordo, livremente e auxiliadas por um terceiro, que consequentemente, deve ser imparcial" (traduzi).
} 
que vivenciam determinados problemas" ". Aludido método extrajudicial de resolução de conflitos proporciona, portanto, as melhores soluções possíveis aos mediados, no sentido de que propicia a construçấo conjunta do acordo, observando-se os interesses de todos os envolvidos. Nesse sentido, lecionam Miranda e Mota:

Dessa maneira, a mediação tenta demonstrar que é possível uma solução para o conflito em que ambas as partes ganhem, tentando, por meio do diálogo, restaurar as benesses que fizeram parte da relação, reconhecer e conhecer os conflitos reais oriundos dos conflitos aparentes perfilados pelos envolvidos, suscitar o questionamento da razão real do desentendimento, provocar a cooperação mútua e o respeito ao próximo ao analisar que cada pessoa tem sua forma de visualizar a questão, facilitar a compreensão da responsabilidade que cada um possui em face do problema e na sua resolução e, assim, encontrar uma saída onde todos aceitem, concordem e acreditem que a divergência será solucionada. ${ }^{9}$

No Brasil, a mediação ganha espaço, de forma contínua, inclusive no âmbito do Poder Legislativo. Nesse sentido, destaca-se a promulgação da Lei $n^{\circ}$. 13.140/2015, a qual dispóe sobre a mediação entre particulares e sobre a autocomposição de conflitos no âmbito da administração pública. Ademais, ressalta-se o Código de Processo Civil de 2015, que estabelece sessão exclusivamente direcionada a conciliadores e mediadores judiciais, evidenciando, ainda mais, a importância do aludido instituto.

A facilitação da comunicação efetiva enseja a aproximação dos mediandos, de forma que eles próprios, com o auxílio do mediador, identificam os pontos negativos e os aspectos positivos, proporcionando a adequada compreensão da situação existente.

A norma jurídica, por si só, pode não ser apta a reconhecer, de forma suficiente, eventuais adversidades pessoais. A mediação, por sua vez, possui a faculdade de maximizar alternativas ao, inclusive, averiguar situações ocultas, as quais nem sequer são explicitamente indicadas pelos participantes. Nesse sentido, abordando a identificação de aspectos supostamente invisíveis, leciona Warat:

A mente é a criadora dos conflitos quando não está em sintonia com

$8 \quad$ SALES, L. M. de M. Mediare (um guia prático para mediadores), 2004.21 p. 361.

9 MIRANDA, A. K. P. C.; MOTA, M. G. O ensino de mediação de conflitos na formaçáo policial: avanços e fragilidades. VIII Conferencia Internacional del Foto Mundial de Mediacion: Tiempo de mediación, liderazgo y acción para el cambio. Libro Digital. Volumen 1. Valencia, España, 18-21 Octubre, 2012, pp. 34-35. 
o sutil e com o invisível. O invisível é o que não pode ser visto no comum das coisas, pois se precisa de olhos mais refinados. A consciência mediadora vem através da sensibilidade que é uma percepção sutil do invisível, uma percepção sutil que unicamente se ganha pela espontaneidade. ${ }^{10}$

Noutra esteira, é importante ressaltar que a mediação contribui com o Poder Judiciário, uma vez que evita a judicializaçáo de demandas ao propiciar resoluçóes extrajudiciais e descentraliza parte do exercício jurisdicional. Vasconcelos esclarece:

É, portanto, através da desjudicialização que se concretiza a descentralização de parte das atividades jurisdicionais. Com ela, setores da sociedade praticam atos que antes eram de exclusividade do Poder Judiciário, contribuindo, dessa forma, para a administração da justiça e para o efetivo acesso à ordem jurídica justa. ${ }^{11}$

A despeito do auxílio que a mediação proporciona à desobstrução do Poder Judiciário, esse aspecto é apenas uma consequência do referido método alternativo de resolução de conflitos. A principal finalidade da mediação é o resgate do diálogo entre os mediandos por meio da sistematização da linguagem por um terceiro aceito. Assim, propicia-se a percepção do conflito. ${ }^{12}$

Ressalta-se, ainda, que os métodos extrajudiciais de resolução de conflitos não são promovidos apenas pelo Poder Judiciário. Há instituiçôes essenciais à função jurisdicional que estabelecem programas que abordam a mediação, a exemplo da Defensoria Pública.

\section{A MEDIAÇÁO NA DEFENSORIA PÚBLICA}

A Defensoria Pública é a instituição que fornece assistência jurídica gratuita aos indivíduos que apresentam determinada vulnerabilidade - social ou econômica. Prevista no art. 134 da Constituiçăo Federal Brasileira de 1988, a Defensoria Pública desempenha função essencial jurisdicional do Estado, assegurando a

\footnotetext{
10 WARAT, L. A. Surfando na pororoca: oficio do mediador, 2004, p. 25.

11 VASCONCELOS, F. H. de. Advocacia negocial: promoção do acesso à justiça pela desjudicialização dos conflitos, 2014, pp. 134-135.

12 DIAS, M. T. F. (Coord.). Mediaçáo, cidadania e emancipaçáo social: a experiência da implantação do centro de mediação e cidadania da UFOP e outros ensaios, 2010, pp. 45-47.
} 
preservação do regime democrático e a promoção dos direitos humanos. Assim, "podem recorrer à Defensoria os necessitados, grupos minoritários hipossuficientes, assim como crianças e adolescentes" ${ }^{13}$.

Referida instituição, portanto, assegura, conforme já mencionado, a efetivação do Estado Democrático de Direito, previsto no art. $1^{\circ}$, caput, da Constituição Federal, estimulando a cidadania e a dignidade da pessoa humana ao garantir, aos assistidos, ferramentas de oposição ao arbítrio e à injustiça. ${ }^{14}$ Aludido panorama é evidenciado mediante a previsão do art. 30-A, incluído pela Lei Complementar 132, de 2009, que prevê, como objetivo da Defensoria Pública, a consolidação do Estado Democrático de Direito.

A relevância da Defensoria Pública é enorme, aspecto esse que se evidencia pela característica de suas funçóes, essenciais para a sociedade. Nesse sentido, é imprescindível que a administração governamental reconheça a devida importância da Defensoria Pública e providencie os devidos recursos para que o trabalho desenvolvido seja efetivo. Todavia, observam-se dificuldades no que concerne ao adequado reconhecimento por parte dos governos. Sobre o tema, esclarece Moreira:

As Defensorias Públicas, notadamente, nem sempre conseguem imprimir a seu trabalho a eficiência desejável, apesar da competência e da dedicação de tantos defensores. Equipará-las bem é tópico que precisaria assumir posição de maior relevo nas escalas de prioridade da administração pública; mas o que se vê, no particular, é a frequente incoerência entre a declarada preocupação social de muitos governos e o descaso na prática voltado ao assunto. ${ }^{15}$

A Lei Complementar n ${ }^{\circ} .80$, de 12 de janeiro de 1994, possui a finalidade de organizar a Defensoria Pública, prescrevendo normas de organização, princípios e diretrizes vinculadas à instituição. Seu art. $2^{\circ}$ indica que referida instituição abarca a Defensoria Pública da Uniâo, a Defensoria Pública do Distrito Federal e dos Territórios e as Defensorias Públicas dos Estados.

13 BANDEIRA, R. Defensoria pública e Ministério Público - o que faz cada um? Disponível em: <http://www.cnj.jus.br/noticias/cnj/77307-defensoria-publica-e-ministerio-publico-o-que-faz-cada-um>. Acesso em: 15 out. 2016.

14 VASCONCELOS, F. H. de. Advocacia negocial: promoção do acesso à justiça pela desjudicialização dos conflitos, 2014, p. 121.

15 MOREIRA, J. C. B. Efetividade do processo: por um processo socialmente efetivo. In: Revista Síntese de Direito Civil e Processual Civil, 2011, p, 10. 
O art. $1^{\circ}$ da citada Lei, com redação dada pela Lei Complementar no ${ }^{\circ}$ 132/2009, estabelece que a Defensoria Pública é instrumento do regime democrático, prevendo "a orientação jurídica, a promoção dos direitos humanos e a defesa, em todos os graus, judicial e extrajudicial, dos direitos individuais e coletivos, de forma integral e gratuita, aos necessitados". ${ }^{16}$ Vê-se, desse modo, a menção expressa à atuação extrajudicial.

Em seu art. $4^{\circ}$, referida Lei estabelece as funçóes institucionais da Defensoria Pública. Entre elas, destacam-se a promoção prioritária da solução extrajudicial dos litígios visando à composição entre as pessoas em conflito de interesses, por meio de mediação, conciliação, arbitragem e demais técnicas de composiçâo e administração de conflitos; o incentivo à difusão e a conscientização dos direitos humanos, da cidadania e do ordenamento jurídico, e o fornecimento de atendimento interdisciplinar, por meio de órgãos ou de servidores de suas Carreiras de apoio para o exercício de suas atribuiçóes.

Nesse contexto, importante ressaltar que o trabalho realizado por defensores públicos abarca não apenas o manuseio de açóes judiciais e de eventuais recursos, como também as orientações jurídicas prestadas aos assistidos e as atuaçóes extrajudiciais propostas. ${ }^{17}$

A Defensoria Pública da União confeccionou o processo de planejamento estratégico, em 2012, destacando, dentre os valores organizacionais, o privilégio de soluçóes extrajudiciais ${ }^{18}$. Nesse sentido, Godoy afirma que "a via judicial deve ser utilizada não mais como recurso primeiro, mas sim quando inviável a implementaçáo de instrumentos que viabilizem a autocomposição". ${ }^{19}$

Ademais, o citado plano estratégico elencou diversas perspectivas e objetivos estratégicos vinculados à atuação da Defensoria Pública da Uniāo. Assim, foram assinaladas propostas

16 BRASIL. Lei Complementar no. 80, de 12 de janeiro de 1994, que organiza a Defensoria Pública da União, do Distrito Federal e dos Territórios e prescreve normas gerais para sua organização nos Estados, e dá outras providências. Disponível em: <http://www.planalto.gov.br/ccivil_03/leis/LCP/Lcp80.htm>. Acesso em: 17 mar. 2017.

17 VASCONCELOS, F. H. de. Advocacia negocial: promoção do acesso à justiça pela desjudicialização dos conflitos, 2014, p. 122.

18 BRASIL. Defensoria Pública da União - Assessoria de Planejamento, Estratégia e Modernização da Gestão. Assistência jurídica integral e gratuita no Brasil: um panorama da atuação da Defensoria Pública da Uniấo, 2015. Disponível em: <http://www.dpu.def.br/images/stories/arquivos/PDF/Mapa_dpu_2015_ web.pdf>. Acesso em 18 mar. 2017.

19 GODOY, A. E. de. Conflitos habitacionais urbanos: atuação e mediação jurídico-política da defensoria pública, 2015, p. 142. 
vinculadas a orçamento e finanças; pessoas, infraestrutura e tecnologia; processos internos; e resultados institucionais. No que tange a estes, ressalta-se a ampliação da atuação extrajudicial, evidenciando que, no âmbito da Defensoria Pública da União, visa-se à promoção prioritária da solução extrajudicial dos litígios, nos termos do art. $4^{\circ}$, inciso II, da Lei Complementar nº. 80/1994.

Complementarmente, destaca-se a Secretaria de Conciliação Extrajudicial e Educação em Direitos (SCE), órgão da Administração superior da Defensoria Pública da União - vinculado à Secretaria-Geral de Articulação Institucional -, que, além de outras competências, incentiva a atuação extrajudicial da aludida instituição.

Ainda no âmbito da Defensoria Pública da Uniāo, foi realizada pesquisa para identificar os principais órgãos de onde originam-se os litígios. Verificou-se que, entre janeiro de 2011 e dezembro de 2015, o Instituto Nacional do Seguro Social (INSS), o Ministério Público da União (MPU), a União e a Caixa Econômica Federal (CEF) representaram $86 \%$ das demandas da Defensoria Pública. ${ }^{20}$

Dessa maneira, foram efetuados termos de colaboração - com ênfase na atuação extrajudicial - com o INSS e com a CEF, o que gerou notável diminuição da quantidade de processos judiciais, proporcionando, desse modo, celeridade no atendimento aos assistidos em assuntos vinculados à previdência social e aos contratos bancários da Caixa Econômica Federal.

Ainda nesse contexto, de acordo com pesquisa realizada pela Defensoria Pública da União, essa instituição realizou, em 2015, 9.742 conciliaçôes extrajudiciais. Ainda de acordo com os dados coletados, o aumento do número de conciliaçóes extrajudiciais efetuadas pela Defensoria Pública da União entre 2011 e 2015 foi de 111\%, o que evidencia, mais uma vez, o encorajamento no que concerne às práticas extrajudiciais. ${ }^{21}$

Entre os programas elaborados pela Defensoria Pública da Uniáo, cita-se o Projeto de

20 BRASIL. Defensoria Pública da União - Assessoria de Planejamento, Estratégia e Modernização da Gestão. Assistência jurídica integral e gratuita no Brasil: um panorama da atuação da Defensoria Pública da Uniâo, 2015. Disponível em: <http://www.dpu.def.br/images/stories/arquivos/PDF/Mapa_dpu_2015_ web.pdf>. Acesso em: 18 mar. 2017.

21 BRASIL. Defensoria Pública da União - Assessoria de Planejamento, Estratégia e Modernizaçáo da Gestão. Assistência jurídica integral e gratuita no Brasil: um panorama da atuação da Defensoria Pública da União, 2015. Disponível em: <http://www.dpu.def.br/images/stories/arquivos/PDF/Mapa_dpu_2015_ web.pdf>. Acesso em: 18 mar. 2017. 
assistência jurídica a hansenianos no Maranhão, que venceu, em 2012, a 9a edição do Prêmio Innovare. Entre as finalidades da aludida iniciativa, destacam-se as "açōes relacionadas à reestruturação física do Hospital Aquiles Lisboa, a concessão de pensão especial a indivíduos submetidos à internaçáo compulsória e o fornecimento de próteses e órteses". ${ }^{22}$

O Projeto de assistência jurídica a hansenianos no Maranhão possui "foco em mecanismos extrajudiciais de assistência e articulação com setores do governo e da sociedade civil, a fim de assegurar os direitos e resgatar a cidadania de pessoas atingidas pela doença" ${ }^{22}$ Vê-se, novamente, o incentivo à atuação extrajudicial.

Noutra esteira, cita-se o positivo estímulo à promoçáo de procedimentos extrajudiciais realizado pela Defensoria Pública do Rio Grande do Sul, que, de acordo com seu relatório anual referente a 2016, realizou 20.169 atuaçóes extrajudiciais, o que revela outro exemplo do implemento do art. $4^{\circ}$, inciso II, da Lei Complementar n ${ }^{\circ} .80 / 1994 .^{23}$

Ademais, a Defensoria Pública do Rio Grande do Sul promove, mediante convênio firmado há oito anos com a Clínica de Psicoterapia e Instituto de Mediação, resoluçóes extrajudiciais de conflitos. Entre agosto de 2015 e julho de 2016, a equipe realizou o atendimento de 288 casos, sendo que o percentual de êxito na celebração de acordos foi de $62 \% .{ }^{24}$

Além das iniciativas indicadas, ressalta-se a Câmara de Resolução de Litígios de Saúde (CRLS), na qual há participação da Defensoria Pública do Rio de Janeiro, da Defensoria Pública da União e de outros órgãos públicos. Inaugurada em setembro de 2013, a CRLS tem por escopo o "atendimento a pessoas de baixa renda promover a solução de problemas relacionados a pedidos de medicamentos, cirurgias e exames médicos pela via administrativa, evitando açóes na Justiça”. 25

22 BRASIL. Defensoria Pública da União em Santa Catarina. Defensoria Pública da Uniáo recebe Prêmio Innovare por assistência a hansenianos no Maranháo. Disponível em: <https://dpusc.wordpress. com/2012/11/08/defensoria-publica-da-uniao-recebe-premio-innovare-por-assistencia-a-hansenianos-nomaranhao/>. Acesso em: 18 mar. 2017.

23 BRASIL. Defensoria Pública do Rio Grande do Sul. Relatório Anual. Disponível em: http:// www.defensoria.rs.def.br/lista/366/relatorio-anual. Acesso em: 17 mar. 2017.

24 BRASIL. Defensoria Pública do Rio Grande do Sul. Relatório Anual. Disponível em: http:// www.defensoria.rs.def.br/lista/366/relatorio-anual. Acesso em: 17 mar. 2017.

25 BRASIL. Associação Nacional dos Defensores Públicos Federais. Duas práticas da Defensoria

Pública da Uniáo concorrem ao Prêmio Innovare. Disponível em: http://www.anadef.org.br/ultimasnoticias/1-latest-news/3539-duas-praticas-da-defensoria-publica-da-uniao-concorrem-ao-premio-innovare. Acesso em: 18 mar. 2017. 
Nesse contexto, de acordo com dados fornecidos pela Associação Nacional dos Defensores Públicos Federais, em seis meses de funcionamento da CRLS, 40\% dos casos apreciados foram solucionados administrativamente, o que demonstra o êxito da aludida iniciativa. ${ }^{25}$

Outro exemplo de projeto que visa à resolução extrajudicial de litígios no âmbito da Defensoria Pública é o Projeto de Mediação e Conciliação para Resolução de Conflitos Extrajudiciais, promovido pela Defensoria Pública do Distrito Federal.

\section{O PROJETO DE MEDIAÇÁO E CONCILIAÇÁO PARA RESOLUÇÁO DE CONFLITOS EXTRAJUDICIAIS}

O Projeto de Mediação e Conciliação para Resolução de Conflitos Extrajudiciais, no âmbito da Defensoria Pública do Distrito Federal, foi instituído informalmente em 2012 e oficializado, mediante ato do Defensor Público-Geral da Defensoria Pública do Distrito Federal, no ano subsequente.

O Tribunal de Justiça do Distrito Federal e Territórios promoveu, em 2012, cursos de mediação visando à capacitação de alguns de seus servidores. Nesse contexto, disponibilizaram-se vagas para entidades vinculadas ao Judiciário, a exemplo da Defensoria Pública do Distrito Federal. Assim, concretizou-se a participação de alguns servidores dessa instituição, que observaram a adequação entre os serviços oferecidos pela Defensoria Pública e a mediação. Ao final dos cursos, foram capacitadas dez mediadoras, as quais implementaram a mediação na seara da aludida instituição. Atualmente, existem aproximadamente vinte e quatro servidores capacitados para realizar mediaçóes no âmbito da Defensoria Pública do Distrito Federal.

Após a verificação dos benefícios resultantes do referido curso, o Defensor Público-Geral da Defensoria Pública do Distrito Federal instituiu, por intermédio da Portaria no . 112, de 20 de setembro de 2013, o Projeto de Mediação e Conciliação para Resolução de Conflitos Extrajudiciais, que foi fundamentado na Lei Complementar n. 80, de 12 de janeiro de 1994.

De acordo com a Portaria n. 112, o citado Projeto considerou que a resolução extrajudicial de litígios promove a conciliação dos envolvidos e obsta a judicialização de demandas. Ademais, consignou que havia necessidade de estabelecer, na Defensoria Pública do 
Distrito Federal, serviços de atendimento direcionados à resolução extrajudicial de litígios. Ademais, indicou-se que o instrumento de transação, mediação ou conciliação referendado pelo Defensor Público tem natureza jurídica de título executivo extrajudicial, conforme dispóe o art. 784, IV, do Código de Processo Civil Brasileiro de 2015, e o art. $4^{\circ}, \S 4^{\circ}$, da Lei Complementar no ${ }^{\circ} .80 / 1994$.

$\mathrm{O}$ art. $1^{\circ}$ da aludida Portaria indica que as técnicas de mediação ou conciliação serão utilizadas nos casos em que a Defensoria Pública do Distrito Federal identificar sua viabilidade. Desse modo, vê-se que há certa discricionariedade da instituição no que concerne à aplicação dos procedimentos extrajudiciais.

Por sua vez, o art. $2^{\circ}$ da Portaria ${ }^{\circ}$. 112 estabelece que o Projeto seria coordenado pelo Departamento de Atividade Psicossocial (DAP), órgão auxiliar da Defensoria Pública do Distrito Federal que tem "o objetivo de aprimorar o atendimento destinado à garantia dos direitos da população em situação de vulnerabilidade social, assim como promover a qualidade do serviço por meio de atendimento técnico". A assistência técnica é realizada por equipes interdisciplinares, formadas por psicólogos, assistentes sociais e pedagogos. ${ }^{26}$

A proposta das mediações no âmbito da Defensoria Pública do Distrito Federal diverge das resoluçóes extrajudiciais promovidas pelo Tribunal de Justiça Distrital, uma vez que aquela ocorre em momento anterior à propositura de eventual açáo judicial, enquanto estas são realizadas durante o trâmite processual, em razão de solicitação do magistrado ou das próprias partes. Isso ocorre porque a Defensoria Pública é o instrumento de acesso ao judiciário por parte de indivíduos hipossuficientes, crianças e adolescentes. Desse modo, os servidores da aludida instituição poderão efetivar a mediação antes da propositura de ação judicial caso verifiquem a possibilidade e viabilidade desse método extrajudicial.

De acordo com entrevista concedida por Aline de Cassia Teixeira Santos, mediadora da Defensoria Pública do Distrito Federal, as mediações realizadas podem abordar questôes cíveis ou de família, mas, na prática, observa-se que referidos procedimentos extrajudiciais abarcam majoritariamente aspectos relacionados ao direito de família. ${ }^{27}$

26 BRASIL. Defensoria Pública do Distrito Federal. Carta de Serviços da Defensoria Pública do Distrito Federal. DPDF, Brasília, Edição 2013. Versão única, p. 26. Disponível em: < http://www.brasilia. df.gov.br/wp-conteudo/uploads/2015/10/CARTA-DE-SERVI\%C3\%87OS-AO-CIDAD\%C3\%83ODEFENSORIA-reduzido.pdf>. Acesso em: 16 out. 2016.

27 SANTOS, A. de C. T. Entrevista concedida a Guilherme Gomes Vieira. Brasília, 18 out. 2016. Disponível em: https://www.youtube.com/watch?v=pvBtqh14u_k. Acesso em: 16 nov. 2016. 
Para a entrevistada, nas mediações, as pessoas chegam com um nível elevado de ruído na comunicação (rompimento, construção inadequada ou inexistência), de forma que a mediação restaura o diálogo ao fazer com que os indivíduos percebam que podem resolver seus próprios problemas.

O pronunciamento judicial nem sempre proporciona a solução desejada pelas partes, de modo que ambas potencialmente podem sair descontentes com o resultado. Assim, a decisão proferida pelo magistrado pode gerar novas adversidades. Por outro lado, solução construída pelas partes é mais duradoura e eficiente, uma vez que se propóe o engajamento na construção de propostas que efetivamente funcionem, não havendo que se falar em terceirização do problema para o juiz.

Aline assevera que as relaçóes familiares possuem um caráter contínuo, sendo necessário que a comunicação flua. Assim, tendo em vista que referidas relações abarcam inúmeras variáveis e sentimentos, o diálogo tende a ser prejudicado. Para resolver aludido impasse, o mediador, por intermédio da utilização de técnicas específicas, proporciona o efetivo diálogo entre as partes e, consequentemente, a construção conjunta da melhor soluçáo possível para todos.

Nesse contexto, a entrevistada aponta que a existência de filhos menores auxilia na resoluçáo dos problemas via mediação, uma vez que, de algum modo, o elo existente entre os pais é mantido. Assim, tendo em vista que as crianças e os adolescentes configuram a parte mais vulnerável das relaçóes familiares, é preciso proteger suas necessidades primordiais. Desse modo, a mediação também auxilia na manutenção da parentalidade, ainda que haja o rompimento da conjugalidade.

Importante ressaltar que, a despeito de a maioria das mediaçóes familiares envolver filhos menores, a inexistência desses não constitui um óbice à mediação, uma vez que o procedimento apresenta benefícios em comparação com a resolução judicial. A diferença corresponde à menor quantidade de variáveis para se gerir, vez que não há, necessariamente, imprescindibilidade na manutenção da relação entre os cônjuges.

No núcleo de atendimento jurídico ao cidadão da Defensoria Pública, local em que Aline trabalha, os indivíduos hipossuficientes passam por orientação técnica, realizada por servidor da instituiçáo, para ter ciência de seus direitos e das alternativas jurídicas que possui. Caso seja identificada a possibilidade e viabilidade de proceder à mediação, explica-se ao interessado o funcionamento do procedimento extrajudicial e é feito um 
convite para sua utilização. Caso a parte demonstre interesse, realiza-se a pré-mediação (sessão individual), aprofundando-se mais no caso concreto. Posteriormente, o servidor entra em contato com a outra parte mediante telefonema, e-mail, fax ou correio. Se houver consentimento, agenda-se um horário para a realização da outra pré-mediaçáo, possibilitando que a outra parte se manifeste. Em seguida, realiza-se a sessão conjunta, viabilizando a construção da melhor solução para as partes.

A depender das circunstâncias do caso concreto, é possível que haja mais de uma sessão conjunta (normalmente quando alguma das partes não dispóe de documentos necessários ou quando há grande polarização das partes, em que não se identifica soluçâo boa para ambas). Para Aline, é importante que o lapso temporal entre as reuniōes não seja amplo (para que as partes não percam o objetivo da mediação) ou curto demais (impossibilitando a reflexão das partes).

Na percepção de Aline, a despeito de não haver dados concretos, muitos dos acordos realizados durante o trâmite processual em causas patrocinadas pela Defensoria Pública do Distrito Federal são fruto da mediação realizada antes da propositura da ação judicial. Para ela, o mais importante não é o acordo, mas sim o aperfeiçoamento da lide sociológica, procedimento no qual os envolvidos têm oportunidade de se questionarem sobre a melhor forma de se relacionar com determinada questão e de resolver o conflito. Segundo a mediadora, é possível que, no momento da mediação, os indivíduos não estejam suficientemente preparados para celebrar um acordo, o que não impede sua realização em momento posterior.

Em entrevista concedida, Cristina Vaz Nery de Brito Pinheiro, mediadora da Defensoria Pública do Distrito Federal, informa que nem todos os centros de atendimento dessa instituição possuem mediadoras à disposição. Apenas os núcleos de defesa da mulher (violência doméstica), da infância e juventude (crianças e adolescentes em estado de risco), de mutirão (itinerante), de atendimento jurídico ao cidadão (iniciais cíveis e de família), do núcleo de defesa do idoso e de iniciais de Brasília (açôes contra a fazenda pública) dispóem de mediadores ${ }^{28}$. Desse modo, considerando que há mais de trinta núcleos da Defensoria Pública espalhados pelo Distrito Federal ${ }^{29}$, percebe-se que o Projeto de Mediaçáo e Conciliação para Resolução de Conflitos Extrajudiciais demanda certa ampliação.

28 PINHEIRO, C. V. N. de B. Entrevista concedida a Guilherme Gomes Vieira. Brasília, 21 out. 2016. Disponível em: https://www.youtube.com/watch?v=tumrq-Hr7BA. Acesso em: 16 nov. 2016.

29 BRASIL. Defensoria Pública do Distrito Federal. Núcleos de Atendimento. Disponível em: $<$ http://www.defensoria.df.gov.br/?page_id=2324>. Acesso em: 21 out. 2016. 
Destaque-se que o Defensor Público-Geral do Distrito Federal anunciou, em 5 de outubro de 2016, a implantação de uma grande unidade de atendimento ao cidadão, localizada em área central de Brasília, sede do Governo do Distrito Federal e capital federal, denominada Defensoria Aqui. Referido centro de atendimento ao cidadão "reunirá, em um único lugar, atendimento inicial nas áreas de habitação, transporte, acessibilidade, saúde, família, direito do consumidor e execução penal. Além disso, contará com um centro de mediação e assistência psicossocial”30.

Tendo em vista que as instalaçóes dos núcleos da Defensoria Pública que dispõem de mediadores não são aptas para a efetiva realização da mediação, a unidade Defensoria Aqui, que possui salas com melhores condiçôes, auxiliará a qualidade do serviço prestado pelos mediadores. Ademais, ampliar-se-á a atuaçáo da mediação no âmbito da Defensoria Pública, vez que outras áreas poderão ser contempladas com o referido procedimento extrajudicial, e que haverá um conjunto fixo de aproximadamente quinze mediadores, os quais serão auxiliados por mediadores de outros núcleos.

Alguns servidores da Defensoria Pública do Distrito Federal estão elaborando um manual prático de mediação para auxiliar os serviços prestados pelos mediadores. Aludido manual demonstrará o passo a passo do procedimento e fornecerá exemplos de formulários utilizados cotidianamente (acordos, atas de ausência, atas de sessōes infrutíferas, atas de desistência ou atas de remarcação). ${ }^{31}$

Cristina informou que, apenas no núcleo de iniciais de Brasília, local onde trabalha, são confeccionados aproximadamente quarenta acordos mensais, dentre os quais $80 \%$ são vinculados a conflitos familiares, em que os assuntos mais comuns são alimentos, acordo de guarda e visita e divórcio. Em relação aos acordos que se referem ao direito de família, de acordo com a mediadora, 90\% deles envolvem a existência de filhos.

Para Cristina, o acordo é sempre a melhor forma de resolver um problema, pois as partes irão formulá-lo, dizer as dificuldades, possibilidades e necessidades, sem haver imposição de terceiros, pois o poder decisório é deles. Ademais, nota-se que a homologaçáo do

30 BRASIL. Defensoria Pública do Distrito Federal. Defensoria Pública do DF abrirá grande espaço de atendimento ao cidadáo. Disponível em: < http://www.defensoria.df.gov.br/?p=24986>. Acesso em: 22 out. 2016.

31 BRASIL. Defensoria Pública do Distrito Federal. Manual Prático Para Mediaçáo da Defensoria é debatido entre servidores do órgáo. Disponível em: < http://www.defensoria.df.gov.br/?p=25050 >. Acesso em: 22 out. 2016. 
acordo, quando necessária, ocorre em, no máximo, trinta dias, o que evidencia a celeridade do procedimento.

Nesse contexto, destaca-se que, diferentemente de compromissos cíveis efetivados pela Defensoria Pública do Distrito Federal, em que o Defensor Público responsável assina - gerando um título executivo extrajudicial -, os acordos que versam sobre matéria de direito de família são homologados por um juiz do Tribunal de Justiça Distrital.

Ainda segundo Cristina, é possível formular acordo em um só dia, caso as partes disponham de tempo. Desse modo, fazem-se sessōes de pré-mediaçẫo com as partes e, posteriormente, sessão conjunta para deliberar e confeccionar o acordo. Ademais, destacase que é possível realizar mediaçóes com pessoas jurídicas, bastando que o representante que compareça às sessóes de mediação seja competente para tanto.

Por fim, ressalta-se relevante ideia efetivada pelo Projeto de Mediação e Conciliação para Resolução de Conflitos Extrajudiciais, no âmbito da Defensoria Pública do Distrito Federal. Nas hipóteses de investigação/negativa de paternidade, caso indivíduos hipossuficientes demandem os serviços da referida instituição, eles serão convidados a participar de sessões de mediação antes de ingressar com ações judiciais.

Se houver consentimento, a Defensoria Pública encaminha solicitação para laboratórios conveniados, os quais realizam os exames de DNA gratuitamente. O resultado, em envelope lacrado, é encaminhado para o Departamento de Atividade Psicossocial juntamente com documento que atesta ou náo a paternidade questionada. Caso haja negativa de paternidade, uma psicóloga do DAP acompanhará o mediador na sessão em que será aberto o envelope com o resultado, justamente com a finalidade de conscientização da função do pai afetivo.

Desse modo, acordos podem ser confeccionados na própria mediação, de forma que as eventuais consequências do resultado do exame de paternidade (ofício a cartórios com a finalidade de retificaçáo de registro; ofício a bancos para criaçáo de contas para depósito de pensão alimentícia; ofício ao empregador do pai para desconto de pensão alimentícia em folha de pagamento; guarda e visita) podem ser acordadas na própria sessão de mediação, evitando que a questão seja judicializada. 


\section{CONSIDERAÇÓES FINAIS}

A mediação constitui instrumento apto a viabilizar a construção conjunta da solução para determinada questão, propiciando uma comunicação efetiva ao empoderar os indivíduos envolvidos. Por meio do referido método alternativo de resolução de conflitos, é possível reconhecer aspectos ocultos e abordar questôes que podem ser consideradas impertinentes no processo judicial, uma vez que há a intensiva participação dos envolvidos no litígio.

Noutra esteira, considerando a crise da jurisdição, em que o Poder Judiciário nem sempre consegue viabilizar o exercício jurisdicional observando a razoável duraçâo do processo, conclui-se que os métodos extrajudiciais de resolução de litígios contribuem decisivamente para a efetivação do acesso à justiça e para a desobstrução do Judiciário.

No que tange à instituição dos aludidos métodos no âmbito da Defensoria Pública, notase que a missão desta instituição é perfeitamente compatível com a aplicação das aludidas ferramentas, uma vez que a própria Lei que organiza as Defensorias Públicas prevê, em seu art. 4º, inciso II, a promoção prioritária da solução extrajudicial dos litígios, inclusive citando expressamente a mediação. Ademais, é interessante consignar que a utilização da mediação em macrolides, visando à confecção e à fixação de teses para demandas repetitivas, constitui aspecto positivo, sobretudo tendo em vista a possibilidade de reduçáo quantitativa de processos em que a Defensoria Pública atua.

Nesse sentido, inúmeros projetos vinculados a atuaçóes extrajudiciais foram instituídos no âmbito das Defensorias Públicas, incluindo o Projeto de Assistência Jurídica a Hansenianos no Maranhão, que venceu a 9a edição do Prêmio Innovare. Ademais, de acordo com os dados fornecidos pelas referidas instituiçôes, nota-se um efetivo estímulo às práticas extrajudiciais.

Por fim, analisou-se o Projeto de Mediação e Conciliação para Resoluçâao de Conflitos Extrajudiciais, promovido pela Defensoria Pública do Distrito Federal, que evidencia o êxito da mediaçáo e a relevância do investimento em formas alternativas de atuação extrajudicial.

Vê-se que devem ser estimulados projetos semelhantes àqueles efetivados pelas Defensorias Públicas da Uniáo, do Rio Grande do Sul, do Rio de Janeiro e do Distrito Federal, uma vez que existem inúmeros benefícios para a Defensoria Pública, para o Judiciário, para as partes e, sobretudo, para a população brasileira. 


\section{REFERÊNCIAS}

ASSOCIAÇÃO NACIONAL DOS DEFENSORES PÚBLICOS FEDERAIS. Duas práticas da Defensoria Pública da Uniáo concorrem ao Prêmio Innovare. Disponível em: http://www.anadef.org.br/ultimas-noticias/1-latest-news/3539-duas-praticas-dadefensoria-publica-da-uniao-concorrem-ao-premio-innovare. Acesso em: 18 mar. 2017.

BANDEIRA, R. Defensoria pública e Ministério Público - o que faz cada um? Disponível em: <http://www.cnj.jus.br/noticias/cnj/77307-defensoria-publica-eministerio-publico-o-que-faz-cada-um>. Acesso em: 15 out. 2016.

BRASIL. Lei Complementar no. 80, de 12 de janeiro de 1994, que organiza a Defensoria Pública da União, do Distrito Federal e dos Territórios e prescreve normas gerais para sua organização nos Estados, e dá outras providências. Disponível em: <http://www.planalto. gov.br/ccivil_03/leis/LCP/Lcp80.htm>. Acesso em: 17 mar. 2017.

CARVAlHO NETTO, M. de. A Hermenêutica Constitucional sob o Paradigma do Estado Democrático de Direito. In: OLIVEIRA, M. A. C. de (coord.). Jurisdiçáo e Hermenêutica Constitucional. Belo Horizonte: Mandamentos, 2004.

CONSELHO NACIONAL DE JUSTIÇA. Dados estatísticos. Disponível em: http:// www.cnj.jus.br/programas-e-acoes/politica-nacional-de-priorizacao-do-1-grau-dejurisdicao/dados-estatisticos-priorizacao. Acesso em: 17 mar. 2017.

DEFENSORIA PÚBLICA DA UNIÃO - ASSESSORIA DE PLANEJAMENTO, ESTRATÉGIA E MODERNIZAÇĀO DA GESTÃO. Assistência jurídica integral e gratuita no Brasil: um panorama da atuação da Defensoria Pública da União. 2. ed. Brasília: DPU, 2015. Disponível em: <http://www.dpu.def.br/images/stories/arquivos/ PDF/Mapa_dpu_2015_web.pdf>. Acesso em 18 mar. 2017.

DEFENSORIA PÚBLICA DA UNIÃO EM SANTA CATARINA. Defensoria Pública da Uniáo recebe Prêmio Innovare por assistência a hansenianos no Maranháo. Disponível em: <https://dpusc.wordpress.com/2012/11/08/defensoria-publica-dauniao-recebe-premio-innovare-por-assistencia-a-hansenianos-no-maranhao/>. Acesso em: 18 mar 2017. 
DEFENSORIA PÚBLICA DO DISTRITO FEDERAL. Carta de Serviços da Defensoria Pública do Distrito Federal. DPDF, Brasília, Edição 2013. Versão única, p. 26. Disponível em: < http://www.brasilia.df.gov.br/wp-conteudo/uploads/2015/10/ CARTA-DE-SERVI\%C3\%87OS-AO-CIDAD\%C3\%83O-DEFENSORIA-reduzido. pdf>. Acesso em: 16 out. 2016.

Defensoria Pública do DF abrirá grande espaço de atendimento ao cidadáo. Disponível em: < http://www.defensoria.df.gov.br/?p=24986>. Acesso em: 22 out. 2016.

Manual Prático Para Mediaçáo da Defensoria é debatido entre servidores do órgáo. Disponível em: < http://www.defensoria.df.gov.br/?p=25050 . Acesso em: 22 out. 2016

Núcleos de Atendimento. Disponível em: <http://www.defensoria.df.gov. br/?page_id=2324>. Acesso em: 21 out. 2016.

DEFENSORIA PÚBLICA DO RIO GRANDE DO SUL. Relatório Anual. Disponível em: <http://www.defensoria.rs.def.br/lista/366/relatorio-anual>. Acesso em: 17 mar. 2017.

DIAS, M. T. F. (Coord.). Mediaçáo, cidadania e emancipaçáo social: a experiência da implantação do centro de mediação e cidadania da UFOP e outros ensaios. Belo Horizonte: Fórum, 2010.

GODOY, A. E. de. Conflitos habitacionais urbanos: atuação e mediação jurídicopolítica da defensoria pública. Curitiba: Juruá, 2015.

MIRANDA, A. K. P. C.; MOTA, M. G. O ensino de mediaçáo de conflitos na formaçáo policial: avanços e fragilidades. VIII Conferencia Internacional del Foto Mundial de Mediacion: Tiempo de mediación, liderazgo y acción para el cambio. Libro Digital. Volumen 1. Valencia, España, 18-21 Octubre, 2012.

MOREIRA, J. C. B. Efetividade do processo: por um processo socialmente efetivo. In: Revista Síntese de Direito Civil e Processual Civil. Porto Alegre: Síntese, maio-jun. 2011.

MUÑOZ, H. S. La mediación: método de resolución alternativa de conflictos en el 
Proceso Civil Español. Revista Eletrônica de Direito Processual, ano 3, v. 3, jan-jun. 2009.

PINHEIRO, C. V. N. de B. Entrevista concedida a Guilherme Gomes Vieira. Brasília, 21 out. 2016. Disponível em: https://www.youtube.com/watch?v=tumrq-Hr7BA. Acesso em: 16 nov. 2016.

SALES, L. M. de M. Mediare (um guia prático para mediadores). 3. ed. Rio de Janeiro: GZ, 2004.

SANTOS, A. de C. T. Entrevista concedida a Guilherme Gomes Vieira. Brasília, 18 out. 2016. Disponível em: https://www.youtube.com/watch?v=pvBtqh14u_k. Acesso em: 16 nov. 2016.

VASCONCELOS, F. H. de. Advocacia negocial: promoção do acesso à justiça pela desjudicialização dos conflitos. João Pessoa: A União, 2014.

WARAT, L. A. Surfando na pororoca: oficio do mediador. ed. Florianópolis: Fundação Boiteux, 2004.

. A promoçáo dos direitos humanos como funçáo moderna da Defensoria. Disponível em: <http://www.conjur.com.br/2015-out-27/tribuna-defensoria-promocaodireitos-humanos-funcao-moderna-defensoria\#_ftnref2>. Acesso em: 10 out. 2016.

SOUSA, J. A. G. de. Uma nova defensoria pública pede passagem: reflexôes sobre a Lei Complementar 132/90. Rio de Janeiro: Lumen Juris, 2011.

. O Destino de Gaia e as funçóes constitucionais da Defensoria Pública: ainda faz sentido (sobretudo após a ediçâo da Lei Complementar 132/09) a visão individualista a respeito da Instituiçáo? In: Revista da Defensoria Pública Geral do Estado do Rio de Janeiro. $\mathrm{n}^{\circ} 25$ (Julho de 2012). Rio de Janeiro: DPGE, 2012. Disponível em: $<$ http:// arquivos.proderj.rj.gov.br/dpge/site/Upload/RD25-175-A-244.PDF>. Acesso em: 10 out. 2016. 